\title{
Fabrication of One-Dimensional Organic Nanostructures Using Anodic Aluminum Oxide Templates
}

\author{
Rabih O. Al-Kaysi, ${ }^{1}$ Tarek H. Ghaddar, ${ }^{2}$ and Gonzalo Guirado ${ }^{3}$ \\ ${ }^{1}$ Department of Basic Sciences, King Saud Bin Abdul-Aziz University for Health Sciences-National Guard Health Affairs, \\ Building Mail Code 3124, Riyadh 11423, Saudi Arabia \\ ${ }^{2}$ Department of Chemistry, American University of Beirut, Beirut 110236, Lebanon \\ ${ }^{3}$ Departamento de Química, Universitat Autònoma de Barcelona, 08193 Bellaterra, Barcelona, Spain \\ Correspondence should be addressed to Rabih O. Al-Kaysi, kaysir@ksau-hs.edu.sa
}

Received 11 December 2008; Accepted 1 February 2009

Recommended by Zhi-Li Xiao

Organic nanostructures are new comers to the fields of nanoscience and nanotechnology. In recent years novel methods for controlling the growth and uniformity of one-dimensional (1D) organic nanostructures (nanowires and nanotubes) have been developing. The use of hard templates as molds for the formation of organic nanowires or nanotubes seems to be a reliable and convenient method. In this review we will discuss the use of anodic aluminum oxide (AAO) templates as the inorganic hard template of choice. We will briefly survey advances in the fabrication of $1 \mathrm{D}$ polymer nanostructures using AAO templates, while the bulk of the review will focus on the synthesis of small molecule nanowires, nanotubes, and nanorods. We will also discuss unique properties of some highly crystalline small molecule nanorods fabricated using AAO templates.

Copyright ( 2009 Rabih O. Al-Kaysi et al. This is an open access article distributed under the Creative Commons Attribution License, which permits unrestricted use, distribution, and reproduction in any medium, provided the original work is properly cited.

\section{Introduction}

Nanomaterial fabrication and nanotechnology have mushroomed in the last four decades. Ever since the famous lecture by Richard Feynman at the 1959 meeting of the American Physical Society at Caltech "There's plenty of room at the Bottom," scientists have taken interest in exploring the nanodimensions of matter. Nanostructures offer properties different from their constituent atoms or the bulk material $[1,2]$.

It is hard to visualize 21st century science without nanotechnology. Everything, from medicine [3] to the clothes we wear, has some sort of nanotechnology weaved into their fabric. The prefix nano has become synonymous with advancement and modern society. This term is being overused in many products for promotional purposes, such as nanoenhanced toothpaste or some other product with "nano" attached to it. Imagine making cigarettes safer by introducing nanoenhanced filters to remove toxic materials from cigarette smoke! It is important to acknowledge that developing novel materials, from which nanostructures are manufactured, is one of the most important tasks of nanotechnology. Thus, chemical synthesis and basic chemistry are still the backbone of nanotechnology.

Materials are generally categorized into organic, inorganic, metallic or composite. Much of the nanotechnology developed so far focused on the fabrication of nanostrucutres composed of metallic or inorganic components. Until recently, people have started investigating the potential use of organic nanostructures. Why did inorganic and metallic, materials take the lead as the materials of choice in nanotechnology? The answer might lie in the nature of the chemical bond that holds organic molecules or inorganic ions together. In an inorganic nanostructure strong ionic bonds hold the structure together. Thus uniform inorganic nanowires, with controllable dimensions, can be grown via chemical vapor deposition method (CVD) on a surface containing inorganic nanoparticle seeds. This method is generally used on most inorganic materials that can be vaporized or synthesized under reduced pressure. Growing inorganic nanostructures, such as quantum dots, can also be size controlled by solution-based chemical capping methods 
[4]. Hence, fabricating inorganic nanostructures is guided by the strong ionic or metallic bond which glues the building blocks of the nanostructure together. However, in the case of organic nanostructures, weak van der Waals or hydrogen bonding forces hold organic molecules together. Thus, many attempts to grow 1D nanostructure via vapor deposition technique did not yield homogeneous nanowires. Instead, platelets, whiskers, or any other shape that is predetermined by the nature of the crystal packing of the organic material is sometimes obtained. It is not always applicable to fabricate organic nanostructures using techniques developed for making inorganic nanostrucutres. There are some exceptions where organic nanostructures can be grown using vapor deposition or by high temperature solid-phase reaction. For example, 1D anthracene and perylene nanorods (average diameter $40 \mathrm{~nm}$ and several microns long) were synthesized by a solid-phase reaction at a temperature close to $340^{\circ} \mathrm{C}$ [5].

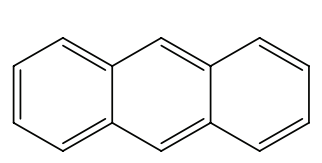

Anthracene

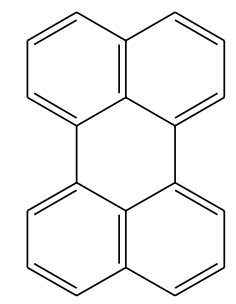

Perylene

1D organic nanostructures have been grown using the principles of supramolecular chemistry and noncovalent interactions. An organic aromatic molecule designed to have a hydrophobic and hydrophilic end can be precipitated from water to form very long self-assembled nanowires [6]. Self-assembled nanowires can also be achieved via $\pi$ $\pi$ interaction and stacking of small molecule semiconductors and conducting polymers [7]. The structure of these nanowires is different than the crystal structure of the bulk material. Another example of supramolecular self-assembly is a molecule containing both donor and acceptor parts. They can be reprecipitated from aqueous solution to form nanoribons, nanotubes, or even nanowires [8]. This method is limited to some molecules and the slightest variation in the chemical structure of the molecule yields different unpredictable supramolecular shapes.

Methods based on reprecipitation (organic nanoparticles) [9-12], vapor deposition [5] (organic nanowires), or self-assembly from aqueous solutions [6] are successful for the synthesis of organic nanostructures made from specific molecules. There are many other techniques for making organic nanostructures, as far as we are aware none of them are high yielding or general methods. It has been accepted for a long time that fabricating organic nanostrucutres was done in clean rooms using expensive Atomic Force Microscopes and nano-FIB machines in well funded research centers (top-down method, through which nanostructures are constructed from the bulk). A general cost effective bench top method of generating large quantities of clone organic nanostrucutres is favored.
This review will focus on the use of anodic aluminum oxide (AAO) templates for the synthesis of $1 \mathrm{D}$ nanostructures made from organic molecules [13]. Nanowires, nanotubes, or nanorods made from small molecule or polymer materials will be surveyed. So far using AAO templates is a general and simple method for fabricating $1 \mathrm{D}$ organic nanostructures.

\section{Anodic Aluminum Oxide (AAO) Templates}

Some metals such as titanium, zirconium, and aluminum form ordered and evenly spaced metal oxide nanopores (in the case of $\mathrm{Al}$ ) or nanotubes (in the case of $\mathrm{Ti}$ ) on the surface of the metal when anodized in an aqueous acidic solution [14]. Anodic aluminum oxide (AAO) membranes are made by a two-step anodization of pure aluminum $(99.99 \%)$ in an acidic solution [15-17]. The aluminum is first annealed in a vacuum oven at $\sim 600^{\circ} \mathrm{C}$ then thoroughly degreased and electropolished. Several factors will determine the size, separation, and length of these honeycombstructured nanopores. Time of anodization will determine the thickness of the membrane, while voltage and type of the electrolyte determine the pore size and separation. Pore size can be custom fabricated from less than $7 \mathrm{~nm}$ to more than $300 \mathrm{~nm}$ and all sizes in between (Figure 1). Varying the potential during the anodization process results in novel nanostructured AAO templates with regular periodic hierarchal branching [18]. AAO templates with cone shaped nanopores were successfully fabricated on small substrates [19]. It has become a common practice to prepare custom AAO templates in the lab. However, Whatman Inc. provides commercial AAO membrane filters (Anodisc-13) with an average pore diameter of $200 \mathrm{~nm}$, a $60 \mu \mathrm{m}$ thick membrane, and a pore density close to $10^{11}$ pores $/ \mathrm{cm}^{2}$. These membranes can withstand high temperatures $\left(\sim 600^{\circ} \mathrm{C}\right)$ without collapsing. Templates with quoted pore diameter of 100 and $20 \mathrm{~nm}$ are only so for the first $2 \mu \mathrm{m}$ of the top layer of the membrane. The rest of the membrane pores are mostly $200 \mathrm{~nm}$ in diameter. Those templates are good for producing 1D nanostructures with a relatively narrow diameter distribution $( \pm 30 \mathrm{~nm})$. The templates are usually ultrasonicated with solvents of varying polarity (water, acetone, ethanol, THF, chloroform) to remove industrial contaminants and to unclog the pores. Then the alumina surface of the nanopores is activated by drying the template in a vacuum oven at a temperature close to $240^{\circ} \mathrm{C}$. Washing the template with a high purity solvent such as THF, by placing it over a glass frit and applying suction, should be sufficient to remove industrial contaminants.

AAO membranes with smaller and more uniform pore diameters and template thickness can be ordered from specialized companies such as Synkera (http://www .synkera.com/). These templates are more expensive. Unlike the Whatman templates, these templates are transparent and more rigid.

Using AAO templates as molds for the synthesis of organic 1D nanostructures is reminiscent to building sand castles at the beach using a bucket to tightly pack a load of 


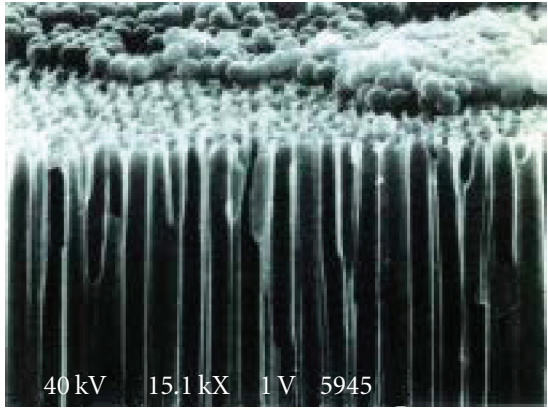

(a)

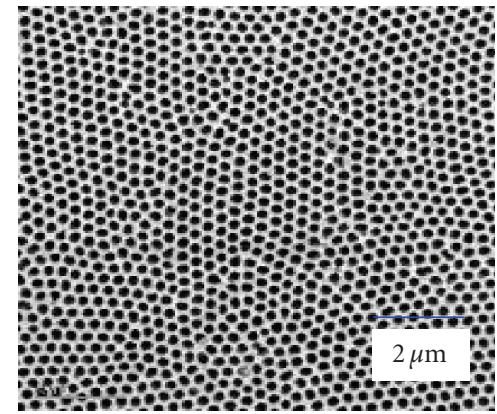

(b)

FIgure 1: (a) Scanning electron microscope (SEM) image of a cross-section of an AAO template with $200 \mathrm{~nm}$ pore diameter. (b) SEM of a $200 \mathrm{~nm}$ AAO template surface collected using a Philip XL30 FEG.

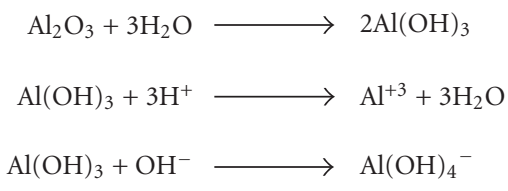

Scheme 1: Hydrolysis and amphoteric reactions of Alumina $\left(\mathrm{Al}_{2} \mathrm{O}_{3}\right)$.

wet sand then slowly removing the mold to form a column. In the case of AAO templates the mold is not gently taped off; instead, it is dissolved away with either an acid or a base. Since aluminum oxide is an amphoteric substance, it could easily be dissolved in aqueous $\mathrm{NaOH}, \mathrm{KOH}$, or an acid such as $\mathrm{H}_{3} \mathrm{PO}_{4}$ (Scheme 1). This made it possible to liberate organic nanostructures that are acid or base sensitive without sacrificing the end product.

\section{One-Dimensional (1D) Organic Nanostructures}

Before expanding on this subject matter, it is desirable to put certain terms in perspective. The term 1D nanostructure is used to describe hair like structure with a large aspect ratio. Aspect ratio is defined as the ratio of the length of the nanowire to its diameter (1):

$$
\text { Aspect Ratio }(\mathrm{AR})=\text { Length/Diameter. }
$$

Throughout this review we will toggle between two similar terms "nanowires and nanorods". By definition, a wire is considered a slender rod. There is no clear cut distinction between a nanorod and a nanowire. Roughly, the aspect ratio of a nanowire is more than 1000 while that of a nanorod is between 3 and 5. A nanowire could be broken down to smaller segments or nanorods. Unfortunately many authors, including the authors of this review, did not make a clear distinction between a nanorod and a nanowire. These two terms were used with disregard to the "aspect ratio" criteria (Figure 2).

When is a nanowire small enough to be worthy of being categorized as a nanostructure? According to the National
Nanotechnology Initiative (NNI), a nanowire is a term applied to a wire with diameter between $1-100 \mathrm{~nm}$, regardless of its length. Nonetheless, throughout the literature surveyed 1D nanostructures with a diameter close to $300 \mathrm{~nm}$ were categorized as nanowires or nanorods. They should be more adequately labeled as "submicron structures." For the sake of this review, let us consider all these 1D structures as nanowires or nanorods regardless of the diameter.

\section{Template Assisted Synthesis of Polymer Nanowires, Nanotubes, and Nanorods}

One of the most convenient, cheapest, and general methods of synthesizing $1 \mathrm{D}$ nanostructures is to use AAO templates as a mold to be filled with the organic material then dissolving away the inorganic template and releasing the nanostructure. The nanostructure will have the same diameter and length of the AAO pores. The chemical literature has several reviews on the use of AAO template to synthesize polymer nanowires or nanotubes $[20,21]$.

It is "easy" to make 1D polymer nanostructures, which are flexible and can withstand the rigor of fabrication. Although the polymer chains are held by weak van der Waals forces, unlike small molecules, these forces are on many sights of the polymer chain thus gripping those chains together and strengthening the polymer.

1D polymer nanostructures were synthesized using template wetting technique. A solution of the polymer was passed through the AAO membrane. Capillary action forced the polymer solution to spread evenly on the inside pores of the AAO template. As the solvent evaporates, a layer of polymer was deposited on the inside walls of the AAO pores. The thickness of the nanotube depended on the concentration of the polymer solution. The more concentrated the solution, the thicker the nanotube wall. This method is limited to polymers that are soluble in organic solvents, and to polymer solutions that have a low viscosity that can allow them to flow through the AAO nanopores.

The first attempt to fabricate $1 \mathrm{D}$ polymer nanostructures was achieved by Martin and coworkers, who synthesized polymer nanotubes by wetting AAO templates with a polymer solution of polystyrene [22-24]. A similar procedure 
was adopted to make polymer nanotubes out of, $\operatorname{poly}(2,6-$ dimethyl-1,4-phenylene oxide), poly(vinylidene fluoride), poly(methyl methacrylate) [22] poly(bisphenol A carbonate), and poly(lactic acid). Formation of hollow nanotubes instead of well-packed nanowires was an unexpected outcome. It was hypothesized that the capillary action inside the AAO nanopores was very strong, forcing the polymer to stick and wet the walls. After the solvent evaporates, the $\mathrm{AAO}$ was etched out using phosphoric acid. The polymer nanotube external diameter was equal to that of the AAO nanopore diameter with a length equal the thickness of the template. The nanotubular morphology was confirmed using electron microscopy. Polymer nanowires were also synthesized using $30 \mathrm{~nm}$ pore size AAO template $[25,26]$. Similar techniques based on wetting template methods were used to synthesize arrays of polymer nanotubes made from conductive polymers [27-29], ferroelectric polymers [30], elastic polymers [31], semiconducting polymers [32], nonpolar polymers [33], poly(vinyl pyrrolidone) [34], and magnetic molecularly imprinted polymers [35]. Insulating polymers such as polyamide 66 were used to make nanotubes to coat Pt nanowires, thus forming nanocables [36-38],

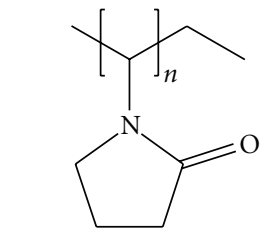

Poly(vinyl pyrrolidone)

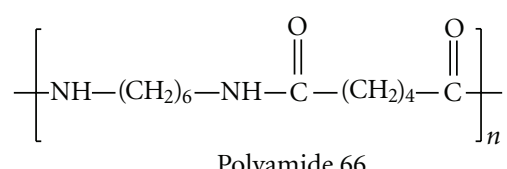

Polyamide 66

So far it seems that wetting an AAO template with a solution of a polymer generates a nanotube after the solvent has evaporated. Nafion-115 nanowires were exclusively formed by wetting AAO template $(85 \mathrm{~nm})$ with the internal walls treated with $1 \%$ sodium dodecylsulfonate (SDS) solution. SDS increased the hydrophobicity of the nanopores forcing the Naflion-115 polymer chains to aggregate together and form a nanowire. Performing a similar procedure on untreated AAO template yields Naflion-115 nanotubes [41]. A similar result was observed when modifying AAO pores with octatrichlorosilane to produce $\mathrm{Al}-\mathrm{OSiC}_{8} \mathrm{O}_{17}$ functionalized alumina surface [34].

Solution-based fabrication of polymer nanotubes was used to prepare PMMA nanotubes doped with tiny amounts of perylene as the fluorescent material. Perylene was added to a 5\% PMMA solution in acetone. The PMMA solution was allowed to pass through an AAO membrane. This process forms perylene doped PMMA nanotubes. While the perylene/PMMA nanotubes were still inside the AAO template "chemically isolated and inert", an aqueous solution of disodium fluorescene (DSF) was passed through. When the AAO was excited with UV light, absorbed by the perylene and not the DSF, the perylene fluorescence was quenched while the DSF fluorescence evolved. This was indicative of an efficient Förster type energy transfer from the perylene (donor) inside the PMMA nanotube to the DSF (acceptor) in solution [42].<smiles>NC(=O)c1ccccc1-c1c2ccc(=O)cc-2oc2cc(O[N+]([O-])O)ccc12</smiles>

DSF

Solution-based formation of polymer nanotubes is a straightforward method for fabricating them. Yet another rout was investigated by which an AAO template is wetted with the molten polymer. This method is limited to polymers that have a low melting point or could flow through nanopores. For an amorphous polymer, it was heated well above its glass transition temperature or melting point in case of a partially crystalline polymer. Polymer nanotubes made from polytetrafluoroethylene (PTFE), polystyrene, or polymethyl methacrylate (PMMA) were successfully fabricated following the above-mentioned method. The nanopore size and period of wetting determine whether researchers obtain a nanotube or a nanowire. For a $200 \mathrm{~nm}$ AAO template brief wetting resulted in polymer nanotubes with wall thickness between 10 and $20 \mathrm{~nm}$, while extended wetting yielded nanowires. For smaller size AAO nanopores wetting the template with molten polymer for brief periods of time produced nanowires [43-45]. Therefore, nanotube or nanowire formation is a function of AAO template pore size. The smaller the nanopore size, the better the chances were for nanowire formation.

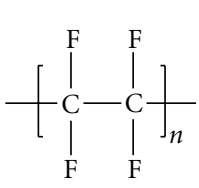

PTFE<smiles>COC(=O)C(C)(C)CC(C)(C)C</smiles>

PMMA

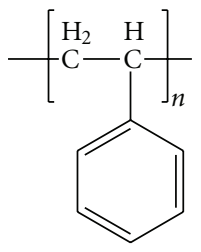

Polystyrene
Electropolymerization is a different method of forming polymer nanowires or nanotubes. This method is limited to certain electron rich aromatic monomers, or monomers that can be electropolymerized. The back of the AAO template is sputter coated with a thin Au film and fixed to the cathode end of an electrochemical cell. The AAO template is immersed in a conducting solution of the monomer. During electrolysis the monomer is attracted to the inside of the AAO template toward the gold layer. Polymerization occurs inside the nanopores gradually forming a polymer nanowire. The length of the nanowire depends on the electrolysis period. The polymer nanowire is then released from the template by first scraping off the metal coating from the back of the AAO template then dissolving away the template with an acid or base. Polypyrrole nanotubes with a $60 \mathrm{~nm}$ external diameter were synthesized by alternating current electropolymerization of a pyrrole solution [46, 47]. It was also revealed that formation of nanotubes or nanowires through electropolymerization depends on the potential as well as monomer concentration. 3,4-ethylenedioxythiophene could 


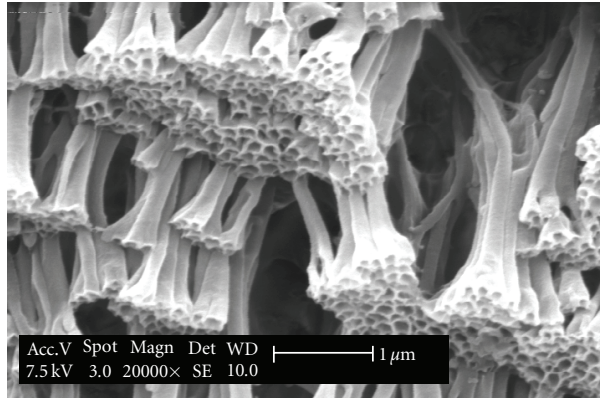

(a)

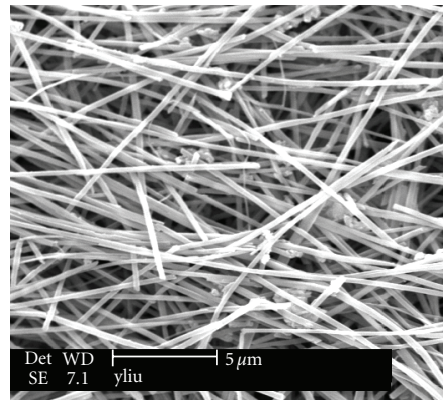

(b)

Figure 2: (a) $200 \mathrm{~nm}$ diameter PMMA nanotubes with their characteristic fluted end [39], (b) 200 nm diameter polymer nanorods or nanowires [40].

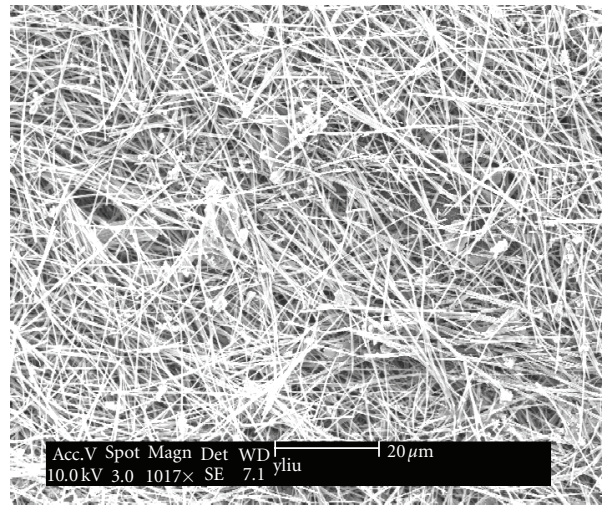

(a)

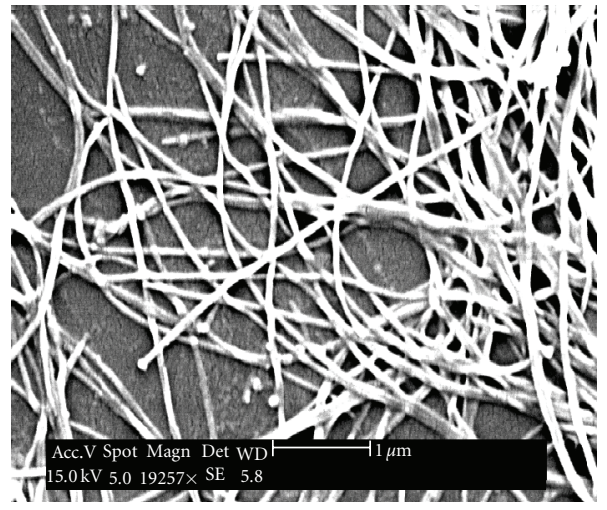

(b)

FIgURE 3: (a) $200 \mathrm{~nm}$ diameter poly(9AC-ME) nanowires [40]. (b) $35 \mathrm{~nm}$ diameter poly(9AC-ME) nanowires [40].

be electropolymerized to Poly(3,4-ethylenedioxythiophene) (PEDOT) nanowires or nanotubes. PEDOT nanotubes were grown at a potential lower than $1.4 \mathrm{~V}$ versus. SCE regardless of the initial concentration of the monomer [48].<smiles>CC(C)(C)c1sc(C(C)(C)C)c2c1OCCO2</smiles><smiles>CC(C)(C)c1ccc(C(C)(C)C)[nH]1</smiles>

Polypyrrole

PEDOT

Another kind of highly crystalline polymer nanowires or nanorods was developed by Al-Kaysi et al. [40]. Photopolymerziation of a photoactive monomer was achieved inside the AAO templates. The first step was to load the AAO template with a concentrated solution of the monomer, in this case 9AC-ME. The solvent was slowly evaporated at elevated temperatures, to yield highly crystalline monomer nanorods. The A-A type monomer units were aligned in an alternating face to face sandwich packing at a distance less than $4 \AA$. Irradiating the loaded AAO template with UV light photopolymerized the monomer to give regioregular poly(9AC-ME) (Scheme 2). The polymer nanorods retained the crystalline order of the monomer to yield very rigid, highly insoluble, highly crystalline polymer. Different diameter poly(9AC-ME) nanowires were synthesized (Figure 3 ). Those nanorods can be unzipped by heating them above $280^{\circ} \mathrm{C}[40]$

\section{Template Assisted Synthesis of Small Molecule Nanowires, Nanotubes, and Nanorods}

It has been previously described in the current manuscript that $1 \mathrm{D}$ polymer nanotubes or nanowires can be formed via AAO template method. Polymers are long molecules with flexible structure that can maintain the $1 \mathrm{D}$ nanostructure morphology after removal from the template. What about small molecules? Can we use AAO template to form 1D nanostructures? The term small molecules will not be limited to molecules with a certain molecular weight threshold. Monomers, PAHs, amino acids, and so forth will be considered. Small molecules, like in the case of polymer chains, are held together by weak van der Waals forces. Unlike in polymers those weak forces are far fewer per molecular unit. Small molecule crystals are softer and more brittle. Nonetheless scientists were able to utilize AAO templates to 


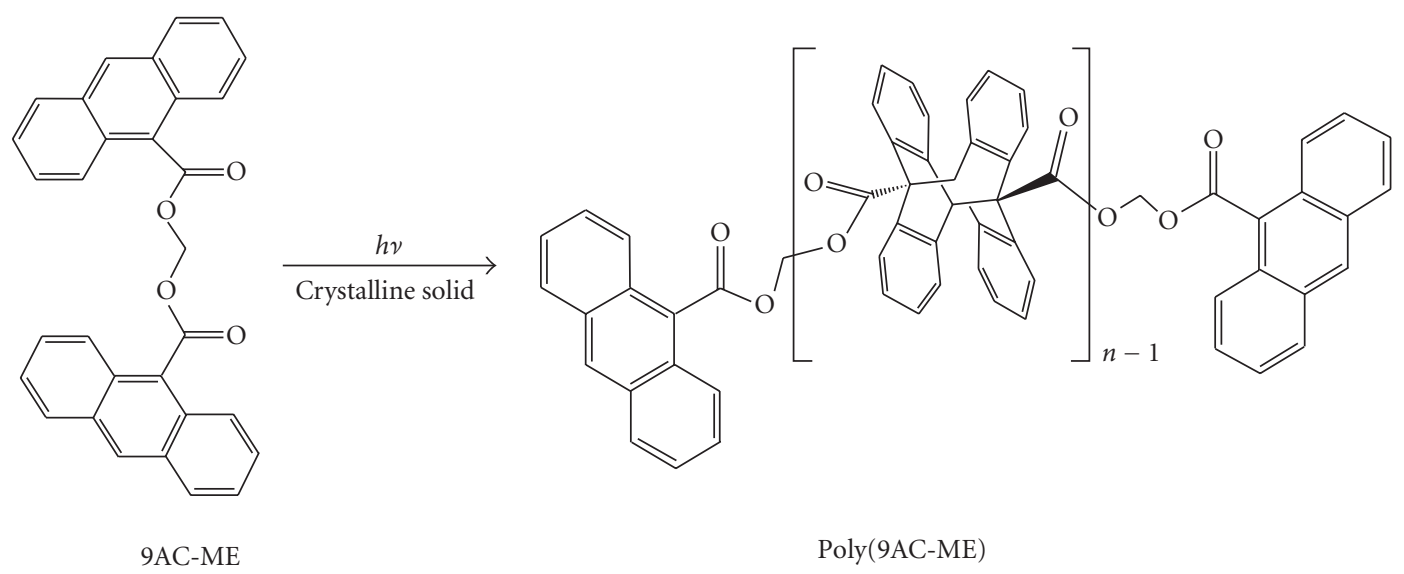

SCHeme 2: $[4 \pi+4 \pi]$ photodimerization of 9AC-ME.

make small molecule nanotubes, nanowires, or nanorods. The chemical literature is still ripe with few examples of small molecule 1D nanostructures. Several methods of 1D small molecule nanostructures will be surveyed.

5.1. Solution-Based Template Wetting Method. When an AAO template is dipped in a solution of the small molecule, the capillary action of the alumina nanopores will soak up the solution rapidly. When the solvent evaporates, the solute is deposited on the nanopore walls because the high surface energy of the pores is stronger than the intermolecular forces. Thus a nanotube is formed. Not only organic small molecules but also organosilanes such as hexaphenylsilole [49] and organometallic complexes such as (Porphryinato)(phthalocyaninato)europium complex [50] were investigated using this methodology. Several small molecules were utilized to fabricate nanotubes or nanowires via solution-based template wetting.

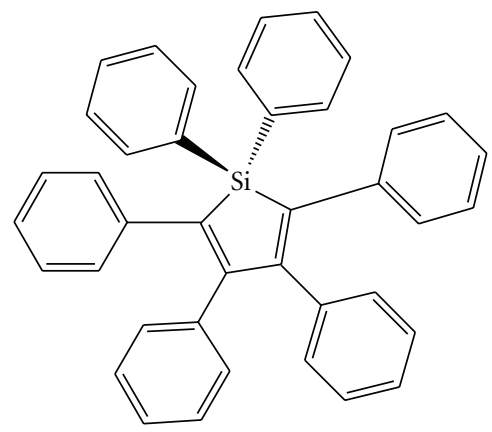

Hexaphenylsilole

Before venturing into the realm of small organic molecule 1D nanostructure, let us consider the case of generating Fullerene nanotubes. $\mathrm{C}_{60}$ is not a small molecule and might not fit in this section of the review, but the method used to form $\mathrm{C}_{60}$ nanotubes paved the way for the incorporation of smaller molecules later on. In this process the cleaned AAO template $(200 \mathrm{~nm})$ was repeatedly dippeddry in a toluene solution of $\mathrm{C}_{60}$. After several cycles the loaded AAO template was thermally annealed at $500^{\circ} \mathrm{C}$ for several hours. The $\mathrm{C}_{60}$ nanotubes were liberated from the AAO template by etching it out with aqueous $\mathrm{NaOH}$. SEM and TEM microscopy confirmed the hollow tubular nature of the $\mathrm{C}_{60}$ nanotubes. Energy-dispersive $\mathrm{X}$-microanalysis confirmed the exclusive carbon content of the nanotube. Electron diffraction pattern revealed that the nanotubes were polycrystalline [51].

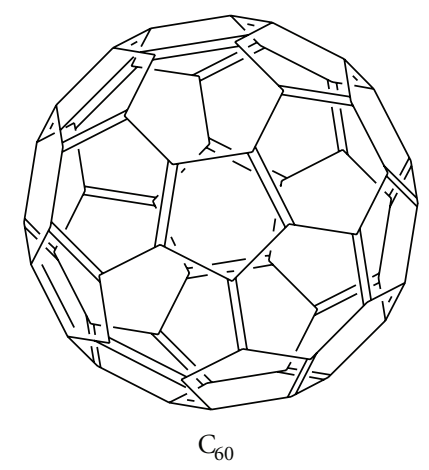

This method was first used in 2002 to prepare perylene nanotubs. A clean AAO template $(200 \mathrm{~nm})$ was dipped-dry several times in a saturated perylene solution. The perylene laden AAO template was thermally annealed at $240^{\circ} \mathrm{C}$ to form perylene nanotubes. The template was removed by dissolving it in an aqueous $\mathrm{NaOH}$ solution. The perylene nanotubes were polycrystalline with a diameter equal the pore diameter and the length was close to the thickness of the template. The tube wall thickness was around $25 \mathrm{~nm}$. Optical spectroscopy of the nanotubes revealed that the perylene was not chemically modified in the process and the perylene units avoided face to face stacking thus preventing the formation of an excimer type fluorescence emission [52]. In an independent attempt to repeat the same experiment using similar preparation techniques and conditions, we found that during the thermal annealing process the perylene usually sublimes out of the nanopores. This would in fact explain the low yield of perylene nanotubes. 


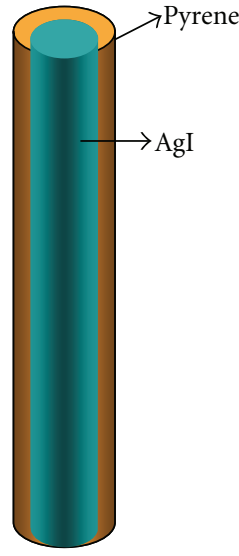

FIgURE 4: Composite pyrene/AgI nanowire.

Pyrene nanotubes (100 nm diameter) were synthesized by the dip-dry method. The formed nanotubes had an evenly deposited thick pyrene coating. These nanotubes serve as a coating for inorganic material to be deposited inside them. An equimolar solution of $\mathrm{AgNO}_{3}$ and $\mathrm{KI}$ in water was allowed to diffuse, with the aid of external pressure, through the templated pyrene nanotubes. The reaction between the $\mathrm{Ag}^{+}$and $\mathrm{I}^{-}$ions precipitated out AgI inside the nanotubes. The AgI nanorods were now coated with the pyrene nanotubes. After the reaction was completed, the template was removed with $\mathrm{NaOH}$ (Figure 4). The composite nature of the nanowire was confirmed by TEM. The electron diffraction pattern showed that the AgI nanowire inside the pyrene nanotube was polycrystalline, so was the pyrene nanotube [53].

Nanotubes made from chiral molecules were also investigated. Concentrated solutions of chiral quinidine in chloroform were filtered through 100 or $140 \mathrm{~nm}$ AAO templates with the aid of an external pressure. The thickness of the nanotube was proportional to the concentration of the solution. Very concentrated solutions yielded quinidine nanowires, while dilute solutions of quinidine failed to nucleate and form nanotubes or nanowires. The loaded AAO templates were then annealed in an oven at $120^{\circ} \mathrm{C}$. This method is different than the dip-dry method previously described. The nanotubes had wall thickness around $30 \mathrm{~nm}$ of crystallized quinidine molecules. The circular dichroism (CD) spectrum of these nanotubes showed ordered interaction between the molecules. This was not observed in the CD spectra of quinidine cast films [54].<smiles>c1cc2ccc3cccc4ccc(c1)c2c34</smiles>

Pyrene

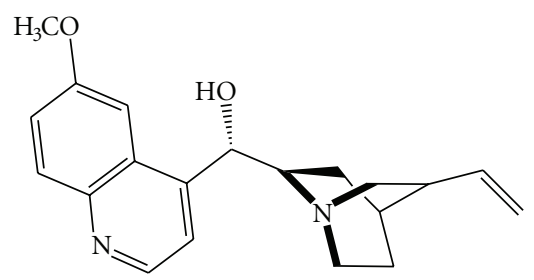

Quinidine
5.2. Melting-Recrystallization Template Wetting Method. In some cases small organic molecules have very low solubility in organic solvents, especially high molecular weight PAHs and perylene-diimide derivatives. The alternative to solution-based template wetting is to melt the organic molecule and wet the AAO template with the molten material. This method can be extended to soluble organic small molecules as well.

Di-benzoylmethane (DBM) is a small organic molecule with a relatively low melting point $\left(80^{\circ} \mathrm{C}\right)$. A molten sample of DBM was prepared and $200 \mathrm{~nm}$ pore diameter AAO template was dipped inside the molten compound. The organic liquid immediately wetted the nanopore walls. It was observed that the longer the immersion time, the thicker the deposited organic layer on the nanopore walls. Tube wall thickness from 20 to $70 \mathrm{~nm}$ was observed with increasing immersion time from 10 to 120 minutes, respectively. Complete filling of the nanopores was prevented due to the strong adhesive forces between the AAO walls and the organic molecules. These forces are stronger than the cohesive forces between the molecules themselves. An Xray diffraction (XRD) of the DBM nanotubes inside the template revealed that the DBM molecules prefer to arrange themselves along the (121) plane. It was also observed that the fluorescence emission from the nanotubes was 4.6 times greater than that from the bulk [55]<smiles>O=C(CC(=O)c1ccccc1)c1ccccc1</smiles>

Dibenzoyl methane

Pentacene is an important PAH used in organic semiconductor technology. It has a very low solubility in organic solvents. When powder pentacene was melted over a $200 \mathrm{~nm}$ AAO template inside a tube furnace under a gentle stream of Argon gas, pentacene nanotubes were formed. Longer thermal annealing times of the molten pentacene result in the formation of nanowires, but not without partial thermal degradation of pentacene. The pentacene nanotubes were liberated from the AAO template and their tubular structure confirmed by TEM and SEM. The tubes had an average length of $15 \mu \mathrm{m}$ and an external diameter close to $200 \mathrm{~nm}$. The tube wall thickness was $40 \mathrm{~nm}$. Powder XRD of the templated pentacene nanotubes revealed that the pentacene units have a short range herringbone packing with the pentacene long axis parallel to the pore length. The low degree of crystallinity of the nanotube did not effect its resistivity which was around $5 \times 10^{5} \Omega \cdot \mathrm{m}[56]$.<smiles>c1ccc2cc3cc4cc5ccccc5cc4cc3cc2c1</smiles>

Pentacene 
5.3. Sublimation Method. Another way of introducing small molecules inside AAO templates is by sublimation. The sublimed small molecules are percolated through the nanochannels where they condense. In the literature, this method was used to make pyrene and 1,4-bis[2-(5-phenyloxazolyl)] benzene (POPOP) nanowires $(20,70$, and $130 \mathrm{~nm}$ in diameter and several micrometers long). The nanowires are most likely polycrystalline in nature, although no evidence of that was presented. The fluorescence spectra of these nanowires showed dependence on the diameter of the nanowire. Thus the $20 \mathrm{~nm}$ diameter nanowires showed monomer like fluorescence, most likely due to the inability of the molecules at the surface to form pairs. The ratio of unpaired molecules at the surface was greater than those paired in the middle of the nanowire. Large diameter nanowires showed fluorescence similar to that of bulk crystals. Unfortunately, the authors of the paper did not elaborate on the experimental conditions for preparing these nanowires [57]. From our experience, subliming small molecules such as anthracene, naphthalene, POPOP, or pyrene close to AAO template results in the immediate clogging of the AAO template pores and growth of crystals on the surface. The authors of [57] must have used heated AAO templates or sophisticated vacuum techniques. This method is limited to small organic molecules that are stable enough to be sublimed, while most small organic molecules melt or decompose instead at elevated temperatures.

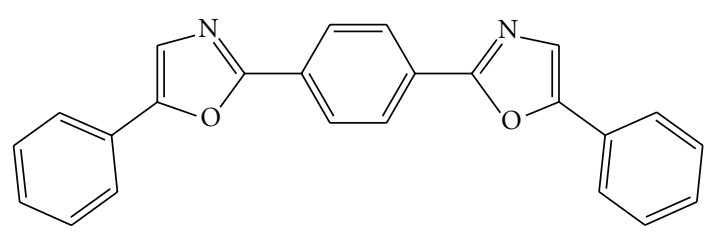

POPOP

5.4. Electrophoretic Deposition Method. Solution and melting recrystalization methods yield nanotubes or nanowires depending on the processing conditions. Electrophoretic deposition is another method of making small molecule nanowires or nanotubes. When one face of an AAO template is coated with a thin film of $\mathrm{Au}$ and affixed to an anode, the bottom side of the pores becomes positively charged and will attract small organic molecules with high electron density.

A 0.1 molar solution of pyrene is prepared in an electrolytic solution of boron trifluoride diethyl etherate (BFEE). When the coated AAO template was used as a working electrode, the pyrene units were eletro-oligomerized, thus forming a continuous nanowire. $200 \mathrm{~nm}$ thick and 60 micron long nanowires of oligopyrene (average number of repeat units $=6$ ) were synthesized. The length of the nanowire could be controlled by the time of electodeposition. The formed nanowires were highly crystalline and exhibited multicolored fluorescence emission depending on the degree of conjugation between the pyrene units in each oligomer [58].<smiles>CC(C)(C)c1ccc2ccc3c(C(C)(C)C)ccc4ccc1c2c43</smiles>

Olygopyrene

Electrophoretic deposition was also used to make chargetransfer salt nanotubes of Bis(ethylenedithio) tetrathiafulvalene (BEDT-TTF). The charge-transfer salt was composed of an alternating layer of BEDT-TTF cation and an anion. A similar method to the one used to prepapre oligopyrene was utilized. The deposited 1D nanostructure was a nanotube instead of a nanowire [59].<smiles>C1CSC2=C(S1)SC(=C1SC3=C(SCCS3)S1)S2</smiles>

Bis(ethylenedithio)tetrathiafulvalene

Perylene-diimide derivatives (PDDs) have important use as dyes and in photoconduction devices. PDDs contain electron rich nitrogen which makes them attracted to the anode in an electrophoretic deposition. Custom made AAO templates ( $80 \mathrm{~nm}$ pore diameter) with the aluminum back still attached to the template served as the anode. Electrophoretic deposition was carried out in a chloroform solution containing $10^{-5} \mathrm{M}$ PDD and trifluoroacetic acid as the protonating agent. The length of the PDD nanowires was proportional to the electrophoretic deposition time. Photoconductive measurement on aligned PDD nanowires showed an order of magnitude more photosensitivity than that of PDD cast films. Indeed this method is a general way for preparing nanowires of n-type PDD molecules. This method is also limited by the law solubility of PDD in organic solvents. Thus longer electrophoretic deposition times will be required $[60]$.

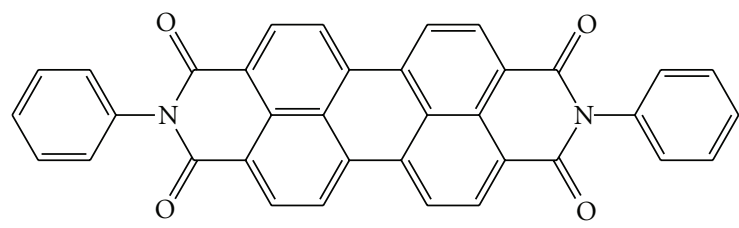

PDD

5.5. Solvent Annealing Method. At this point different methods for making 1D small molecule organic nanostructures have been discussed. Nanotubular structures are thermodynamically favored over a fully packed nanowire due to the strong surface area energy of the AAO nanopores. All these $1 \mathrm{D}$ nanostructures have one thing in common; they are polycrystalline. Regardless of the method of preparation, the 
1D nanostructure formed is held together by polycrystalline or randomly oriented molecular units. The polycrystalline nature of these nanotubes or nanowires was adequately confirmed by the concentric circular pattern of the electron diffraction (ED) from isolated nanotube or nanowire. The polycrystalline nature of these organic nanostructures makes them inferior to their inorganic counterparts, since the latter are highly crystalline and in many cases the whole 1D structure is a single crystal. The hope was to find a general method for making highly crystalline organic 1D nanostructure using AAO templates.

One can start with a large single crystal of an organic small molecule then shave it down "top-down method" to the desirable nanosize. This is an expensive procedure and not for bulk production. Another way of generating highly crystalline 1D organic nanostructures is via selfassembly $[6,8]$. This technique is limited to certain type of organic molecules and yields $1 \mathrm{D}$ nanostructures with varied dimensions.

5.5.1. Experimental Details. A commercially available AAO template (Whatman-13, $200 \mathrm{~nm}, 25 \mathrm{~mm}$ diameter) has enough pores to accommodate a maximum of 6-9 $\mathrm{mg}$ of organic material, assuming that the density of bulk organic small molecules is around $1 \mathrm{~g} / \mathrm{mL}$. Suspend the AAO membrane using specially designed Teflon holder that holds the AAO template from the edge, inside a standard $16 \mathrm{oz}$ jar. Add around $0.2 \mathrm{~mL}$ a concentrated solution of the organic small molecule (10-20 mg in every $0.1 \mathrm{~mL}$ of good solvent) to the surface of the template. The organic solvent used is usually volatile such as dichloromethane, tetrahydrofuran (THF), or Benzene. THF was more often used because it is a good solvent for most organic small molecules. After the solvent has evaporated from the surface of the template, a couple of milliliters of the organic solvent were added to the bottom of the jar. A small vial containing phosphorous pentoxide was placed inside the jar to prevent water contamination and keep the system dry. The jar was tightly covered and a long needle was inserted through the lid to the bottom of the jar. Another needle was inserted in the cover coupled with a gas bubbler. Argon gas was introduced into the jar at a rate of 1 bubble every 8 to 10 second. The slow roomtemperature solvent vapor annealing causes the deposited organic layer on the surface of the AAO template to dissolve in the solvent vapors, while capillary action inside the template prevented the solution from dripping. The organic compound slowly crystallizes in the nanochannels after all the solvent has evaporated (ca. 48 hour). The annealed AAO template surface was polished using 2000 grit sandpaper to remove excess organic layer. The template is etched out using phosphoric or aqueous sodium hydroxide, liberating the nanorods (Figure 5).

Several small organic molecules were used to prepare highly crystalline organic nanowires "referred to as nanorods." 2,7-di-t-butylpyrene [61] was used to prepare the first sample of crystalline nanorods. A modified solvent annealing procedure was used. Instead of room temperature solvent annealing, the jar/AAO template was placed in an oven for 2 days. The solvent used in this case was THF (B.P. $65^{\circ} \mathrm{C}$ ) and the oven temperature was set at 3 degrees above the boiling point of THF. This procedure yielded highly crystalline nanorods. The evidence was established by the unique dot pattern of an ED of a single nanorod. Dark field experiments revealed that the nanorod is a single crystal over a minimum of $15 \mu \mathrm{m}$ length (Figure 6(c)). Other compounds were also used to prepare nanorods, for example, m-terphenyl and 9-cyanoanthracene [61]. It is important to remark that $\mathrm{m}$-terphenyl nanotubes are also obtained by dipping an AAO template in a molten sample. The main drawback associated with the solvent annealing method is the difficulty to prepare nanorods from an organic material that does not have a high solubility in a volatile organic solvent. Thus compounds of electronic importance such as Anthracene and 9,10-diphenylanthracene have a low solubility in THF or dichloromethane; hence, we could not form nanorods. Table 1 contains of a list of some small molecules and solvent annealing conditions used to successfully form nanorods.

\section{Some Unique Properties of Highly Crystalline Small Molecule Nanorods Made Using Solvent Annealing Method}

An interesting case that clearly differentiated 1D organic nanostructures from the bulk was in the use of photoreactive ancthracene ester derivatives. Highly crystalline nanorods of 9-anthracene-t-butylester (9-TBAE) [64], 9methylanthracene and 9-Anthracene carboxylic acid (9-AC) [62], which were made using the solvent annealing method, exhibit unique photomechanical properties. When large micron-sized crystals of 9-TBAE or 9-AC were irradiated with UV light $(365 \mathrm{~nm})$, the crystal photodimerizes via a $[4+4]$ photocycloaddition to form the photodimer. The photochemical reaction produced internal stress that resulted in crystal disintegration. When $200 \mathrm{~nm}$ nanorods of 9-TBAE were irradiated, a clean crystal-crystal transformation was observed with an anisotropic expansion along the long axis. In other cases when $200 \mathrm{~nm}$ (9-AC) nanorods were asymmetrically or partially irradiated, the result is wiggling and micron scale translation of the whole nanorod. The $[4+4]$ photodimerization of 9 -AC is thermally reversible; thus, the nanorod regains its original structure and the mechanical motion could be recycled several times [66]. Coating the 9-AC with a thin layer of silica did not hinder this photomechanical response, which suggests that the amount of energy produced is large enough to overcome the constriction due to a layer of silica, propel the nanorod through solution, and push the micron-sized nanostructures across [39]. Nanorods made from 9-methylanthracene ester (9-MAE) tend to contract along the long axis when irradiated with UV light. This contraction was unexpected since 9TBAE expands instead. This expansion, contraction, or wiggling behavior could be directly explained by the way the crystals pack and rearrange inside the nanorod. C. J. Bardeen group of the department of chemistry at the University of California-Riverside are currently investigating the 
TABLE 1: Some of the small molecules used to make nanorods.

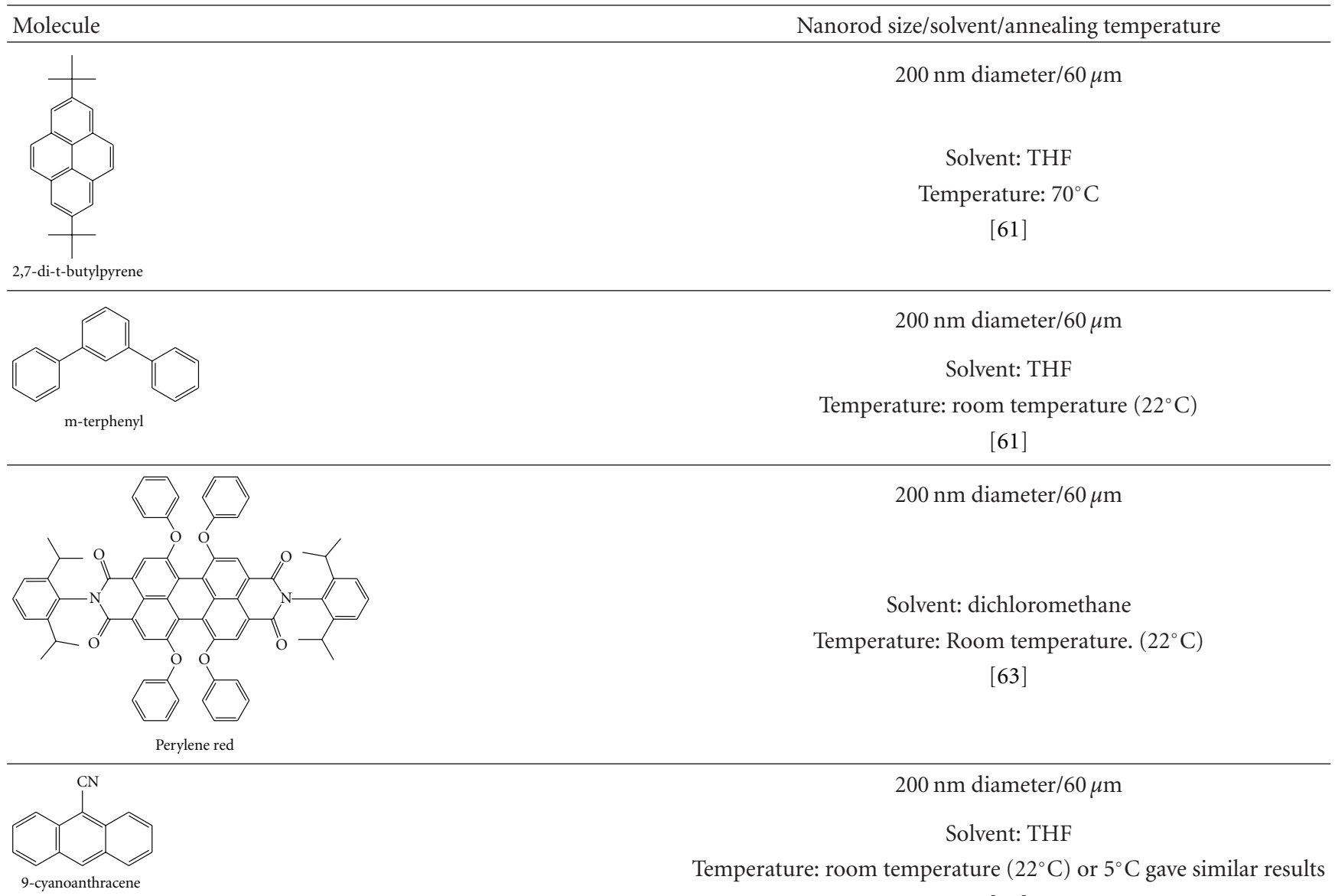

[61]

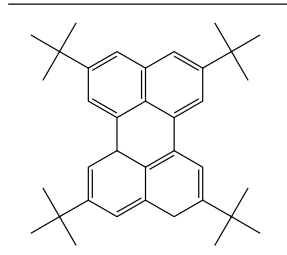

$200 \mathrm{~nm}$ diameter $/ 60 \mu \mathrm{m}$

Solvent: dichloromethane

Temperature: room temperature $\left(22^{\circ} \mathrm{C}\right)$

2,5,8,11-tetra-tert-butylperylene

[61]

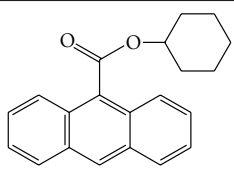

Anthracene-9-carboxylic acid cyclohexyl ester

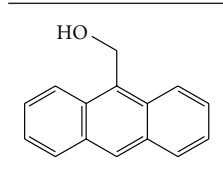

Anthracene-9-yl-methanol

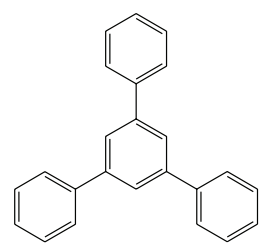

1,3,5-triphenyl benzene
$200 \mathrm{~nm}$ diameter/60 $\mu \mathrm{m}$

Solvent: dichloromethane

Temperature: room temperature $\left(22^{\circ} \mathrm{C}\right)$

[63]

$200 \mathrm{~nm}$ diameter/60 $\mu \mathrm{m}$

Solvent: THF

Temperature: $70^{\circ} \mathrm{C}$

[63]

$200 \mathrm{~nm}$ diameter $/ 60 \mu \mathrm{m}$

Solvent: THF

Temperature: room temperature $\left(22^{\circ} \mathrm{C}\right)$

[61] 
Table 1: Continued.

Molecule

Nanorod size/solvent/annealing temperature

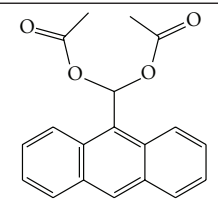

$200 \mathrm{~nm}$ diameter/60 $\mu \mathrm{m}$

Solvent: THF

Temperature: $\left(68^{\circ} \mathrm{C}\right)$

Acetic acid acetoxy-anthracene-9-yl-methyl ester

[63]

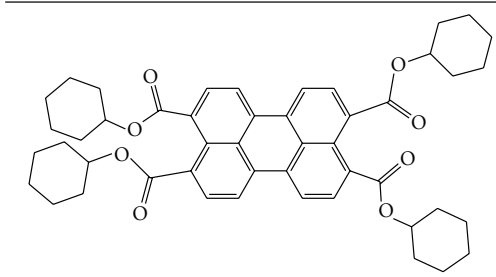

Perylene-3,4,9,10-tetracarboxylic acid tetracyclohexyl ester

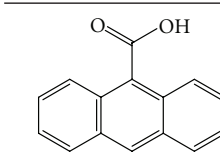

3-anthracene-9-yl-acrylic acid

$200 \mathrm{~nm}$ diameter $/ 60 \mu \mathrm{m}$

$35 \mathrm{~nm}$ diameter $/ 50 \mu \mathrm{m}$

Solvent: THF

Temperature: $70^{\circ} \mathrm{C}$

[63]

$200 \mathrm{~nm}$ diameter $/ 60 \mu \mathrm{m}$

Solvent: THF

Temperature: $68^{\circ} \mathrm{C}$

[63]

$200 \mathrm{~nm}$ diameter $/ 60 \mu \mathrm{m}$

$35 \mathrm{~nm}$ diameter $/ 50 \mu \mathrm{m}$

$13 \mathrm{~nm}$ diameter $/ 50 \mu \mathrm{m}$

Solvent: THF or dichloromethane

Temperature: room temperature $\left(22^{\circ} \mathrm{C}\right)$

[64]

$200 \mathrm{~nm}$ diameter $/ 60 \mu \mathrm{m}$

Solvent: THF, or dichloromethane

Temperature: room temperature $\left(22^{\circ} \mathrm{C}\right)$

[65]

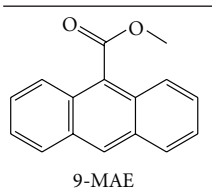

$200 \mathrm{~nm}$ diameter $/ 60 \mu \mathrm{m}$

Solvent: dichloromethane

Temperature: $68^{\circ} \mathrm{C}$

[63]

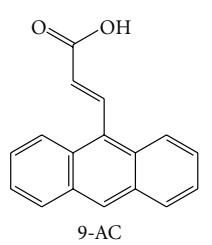

$200 \mathrm{~nm}$ diameter $/ 60 \mu \mathrm{m}$

$35 \mathrm{~nm}$ diameter $/ 50 \mu \mathrm{m}$

$13 \mathrm{~nm}$ diameter $/ 50 \mu \mathrm{m}$

Solvent: THF

Temperature: room temperature $\left(22^{\circ} \mathrm{C}\right)$

$[39,62]$

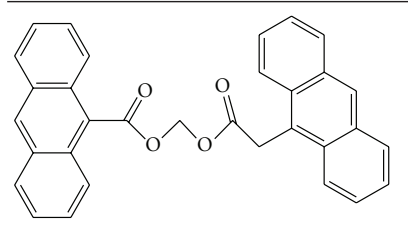

9AC-ME
$200 \mathrm{~nm}$ diameter/60 $\mu \mathrm{m}$

$35 \mathrm{~nm}$ diameter $/ 50 \mu \mathrm{m}$

Solvent: THF

Temperature: $70^{\circ} \mathrm{C}$

[40] 


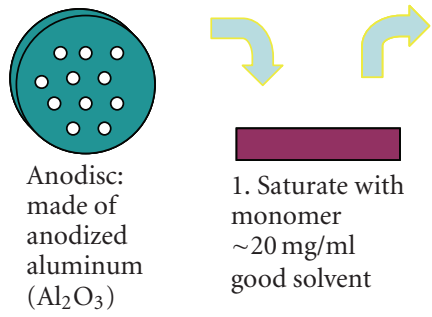

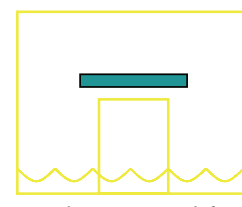

2. Solvent anneal for $\sim 24$ hours

$\sim 5^{\circ} \mathrm{C}$ above solvent boiling point or at room temperature,

till solvent evaporates

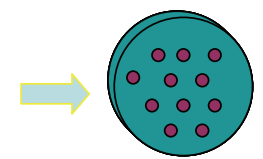

3. Remove excess surface material by polishing

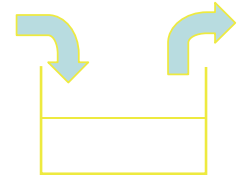

4. Dissolve anodisc template in aqueous base $2 \mathrm{M} \mathrm{NaOH}$ or $25 \% \mathrm{H}_{3} \mathrm{PO}_{4}$

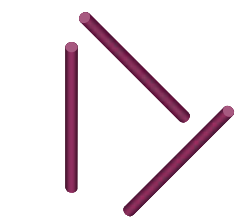

5. Collect isolated nanorods

FIGURE 5: Steps for fabricating solvent annealed molecular crystal nanorods.

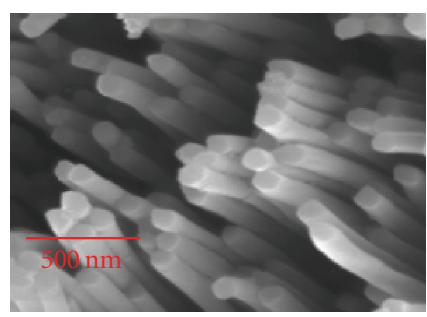

(a)

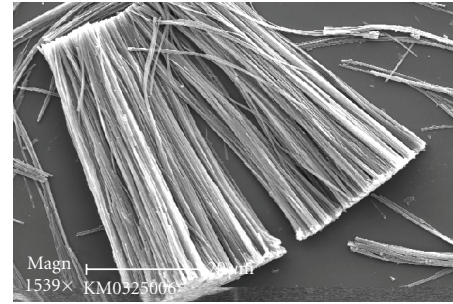

(b)

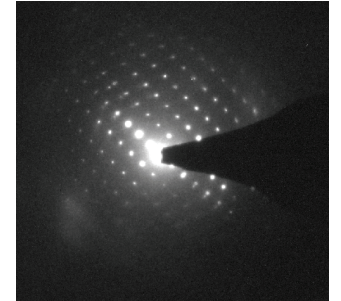

(c)

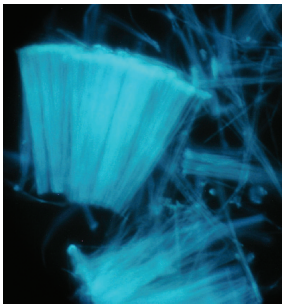

(d)

FIGURE 6: (a) SEM image of a $200 \mathrm{~nm}$ 2,7-di-t-butylpyrene nanorods [61]. (b) SEM image of a $200 \mathrm{~nm}$ 9-anthracene carboxylic acid nanorod bundle [62]. (c) Electron Diffraction pattern of 2,7-di-t-butylpyrene nanorod [61]. (d) Fluorescence microscope image of fluorescent $200 \mathrm{~nm}$ thick 60 micron long nanorods [63].

correlation between crystal structure and photomechanical response of some anthracene derivative nanorods.

Another interesting behavior of some highly crystalline organic nanorods is their ability to form crystalline cocrystal nanorods without loosing their original shape or crystallinity. 9-methyl anthracene nanorods with $200 \mathrm{~nm}$ diameter were fabricated via solvent annealing method. The nanorods were kept inside the template which was suspended in an aqueous suspension of 1,2,4,5-tetracyanobenzene. After several days a solid state diffusion of the TCNB molecules inside the 9-MA nanorods was observed. After removal of the template the nanorods have changed into an intimate $1: 1$ charge-transfer salt of 9-MA:TCNB. The charge-transfer nanorods were single crystals as confirmed by TEM and ED experiments. A similar diffusion experiment on microns-sized single crystal of 9-MA resulted in disintegration of that crystal and formation of the polycrystalline CT complex [65].

\section{Conclusion}

AAO template method is a general way of obtaining organic nanotubes, nanowires, or nanorods of variable length and diameter $(7-400 \mathrm{~nm})$. The use of these templates to generate polymer nanotubes or nanowires has taken precedents over small molecule 1D nanostructures. There are ways for making small molecule nanowires and nanotubes that can withstand the rigger of template fabrication. It is also shown that organic 1D nanostructures could behave in a unique way that differentiates them from the isolated molecule or the bulk. Polymer nanowires made from semiconducting polymers have enhanced resistivity when compared to the bulk or cast film. The unique shape of polymer nanotubes and nanowires exposes a large surface area of the material in a confined space. Thus many polymer nanotubes and nanowires have seen applications in gas sensing analysis and as smart filters. Highly crystalline organic nanorods made from photoreactive small molecules can expand or contract when irradiated with UV light without disintegrating like the larger micron-sized crystals.

\section{Acknowledgments}

The first author would like to acknowledge the King Saud bin Abdul-Aziz University for Health Sciences and the Department of Basic Sciences for financial support. The third author gratefully acknowledges the financial support of the Spanish Ministerio de Educación y Ciencia through Project CTQ2006-01040. The second author acknowledges the financial support of the University Research Board (URB) at the American University of Beirut (AUB) and the Lebanese National Council for Scientific Research (LNCSR). Finally, Professor C. J. Bardeen (University of CaliforniaRiverside) and professor I. Gallardo (Universitat Autònoma of Barcelona) are also acknowledged for helpful discussions.

\section{References}

[1] G. Cao, Nanostructures \& Nanomaterials: Synthesis, Properties \& Applications, Imperial College Press, London, UK, 2004. 
[2] S. Schlitt, A. Greiner, and J. H. Wendorff, "Cylindrical polymer nanostructures by solution template wetting," Macromolecules, vol. 41, no. 9, pp. 3228-3234, 2008.

[3] R. A. Freitas, Nanomedicine, Volume I: Basic Capabilities, Landes Bioscience, Austin, Tex, USA, 1999.

[4] C. N. R. Rao, A. Müller, and A. K. Cheetham, The Chemistry of Nanomaterials, Wiley-VCH, Weinheim, Germany, 2004.

[5] H. Liu, Y. Li, S. Xiao, et al., "Synthesis of organic onedimensional nanomaterials by solid-phase reaction," Journal of the American Chemical Society, vol. 125, no. 36, pp. 1079410795, 2003.

[6] J.-H. Ryu, D.-J. Hong, and M. Lee, "Aqueous self-assembly of aromatic rod building blocks," Chemical Communications, no. 9, pp. 1043-1054, 2008.

[7] A. L. Briseno, S. C. B. Mannsfeld, S. A. Jenekhe, Z. Bao, and Y. Xia, "Introducing organic nanowire transistors," Materials Today, vol. 11, no. 4, pp. 38-47, 2008.

[8] X. Zhang, X. Zhang, B. Wang, et al., "One- or semi-twodimensional organic nanocrystals induced by directional supramolecular interactions," Journal of Physical Chemistry C, vol. 112 , no. 42 , pp. 16264-16268, 2008.

[9] R. O. Al-Kaysi, A. M. Müller, T.-S. Ahn, S. Lee, and C. J. Bardeen, "Effects of sonication on the size and crystallinity of stable zwitterionic organic nanoparticles formed by reprecipitation in water," Langmuir, vol. 21, no. 17, pp. 7990-7994, 2005.

[10] H. Kasai, H. Kamatani, S. Okada, H. Oikawa, H. Matsuda, and H. Nakanishi, "Size-dependent color and luminescences of organic microcrystals," Japanese Journal of Applied Physics, vol. 35, no. 2B, pp. L221-L223, 1996.

[11] E. Van Keuren, E. Georgieva, and M. Durst, "Kinetics of the growth of anthracene nanoparticles," Journal of Dispersion Science and Technology, vol. 24, no. 5, pp. 721-729, 2003.

[12] Z. Jia, D. Xiao, W. Yang, Y. Ma, J. Yao, and Z. Liu, "Preparation of perylene nanoparticles with a membrane mixer," Journal of Membrane Science, vol. 241, no. 2, pp. 387-392, 2004.

[13] A. Thomas, F. Goettmann, and M. Antonietti, "Hard templates for soft materials: creating nanostructured organic material," Chemistry of Materials, vol. 20, no. 3, pp. 738-755, 2008.

[14] Z. Su and W. Zhou, "Formation mechanism of porous anodic aluminium and titanium oxides," Advanced Materials, vol. 20, no. 19, pp. 3663-3667, 2008.

[15] H. Asoh, K. Nishio, M. Nakao, T. Tamamura, and H. Masuda, "Conditions for fabrication of ideally ordered anodic porous alumina using pretextured Al," Journal of the Electrochemical Society, vol. 148, no. 4, pp. B152-B156, 2001.

[16] J. J. Schneider, J. Engstler, K. P. Budna, C. Teichert, and S. Franzka, "Freestanding, highly flexible, large area, nanoporous alumina membranes with complete through-hole pore morphology," European Journal of Inorganic Chemistry, vol. 2005, no. 12, pp. 2352-2359, 2005.

[17] W. Lee, R. Scholz, and U. Gŏsele, "A continuous process for structurally well-defined $\mathrm{Al}_{2} \mathrm{O}_{3}$ nanotubes based on pulse anodization of aluminum," Nano Letters, vol. 8, no. 8, pp. 2155-2160, 2008.

[18] G. Meng, Y. J. Jung, A. Cao, R. Vajtai, and P. M. Ajayan, "Controlled fabrication of hierarchically branched nanopores, nanotubes, and nanowires," Proceedings of the National Academy of Sciences of the United States of America, vol. 102, no. 20, pp. 7074-7078, 2005.

[19] B.-Y. Yoo, R. K. Hendricks, M. Ozkan, and N. V. Myung, “Three-dimensional alumina nanotemplate," Electrochimica Acta, vol. 51, no. 17, pp. 3543-3550, 2006.
[20] S. J. Kim, J. H. Lim, and J. Choi, "Porous inorganic template process for the fabrication of polymer nanotubes and nanowires," Kobunja Kwahak Kwa Kisul, vol. 17, no. 6, pp. 742$751,2006$.

[21] G.-J. Song, J.-J. Li, and X.-L. She, "Research progresses of polymer nanotubes," Polymer Bulletin, vol. 6, no. 74, pp. 31$37,2006$.

[22] H.-J. Oh, Y. Jeong, S.-H. Kwon, C.-H. Heo, B.-S. Ki, and C.-S. Chi, "Fabrication of polymer nanotubes using alumina template," Diffusion and Defect Data, Part B, vol. 124-126, no. 2, pp. 1109-1112, 2007.

[23] G.-J. Song, X.-L. She, and J.-J. Li, "Preparation of polystyrene nanotubes with array structures in anodic aluminum oxide using a simple template method," Qingdao Daxue Xuebao, Gongcheng Jishuban, vol. 19, no. 2, pp. 24-29, 2004.

[24] G.-J. Song, X.-L. She, Z. Fu, and J.-J. Li, "Preparation of good mechanical property polystyrene nanotubes with array structure in anodic aluminum oxide template using simple physical techniques," Journal of Materials Research, vol. 19, no. 11, pp. 3324-3328, 2004.

[25] V. M. Cepak and C. R. Martin, "Preparation of polymeric micro- and nanostructures using a template-based deposition method," Chemistry of Materials, vol. 11, no. 5, pp. 1363-1367, 1999.

[26] X.-L. She, G.-J. Song, Z. Peng, et al., "Preparation of one dimensional polymer nanometer array with polymers solution and melt by wetting AAO template," Xiandai Huagong, vol. 27, no. 11, pp. 34-36, 2007.

[27] S. I. Cho and S. B. Lee, "Fast electrochemistry of conductive polymer nanotubes: synthesis, mechanism, and application," Accounts of Chemical Research, vol. 41, no. 6, pp. 699-707, 2008.

[28] M. Wan, "Conducting polymer nanotubes," in Encyclopedia of Nanoscience and Nanotechnology, H. S. Nalwa, Ed., pp. 153169, American Scientific, Stevenson Ranch, Calif, USA, 2nd edition, 2004.

[29] J. Joo, K. T. Park, B. H. Kim, et al., "Conducting polymer nanotube and nanowire synthesized by using nanoporous template: synthesis, characteristics, and applications," Synthetic Metals, vol. 135-136, pp. 7-9, 2003.

[30] C.-C. Wang, Q.-D. Shen, S.-C. Tang, et al., "Ferroelectric polymer nanotubes with large dielectric constants for potential all-organic electronic devices," Macromolecular Rapid Communications, vol. 29, no. 9, pp. 724-728, 2008.

[31] X.-L. She, G.-J. Song, Z. Peng, J.-J. Li, P. Han, and S.-L. Wang, "EVA Nanotubes fabricated by wetting of anodic aluminum oxide (AAO) template," Xiandai Huagong, vol. 27, no. 1, pp. 169-171, 2007.

[32] S. Moynihan, D. Iacopino, D. O'Carroll, H. Doyle, D. A. Tanner, and G. Redmond, "Emission color tuning in semiconducting polymer nanotubes by energy transfer to organolanthanide dopants," Advanced Materials, vol. 19, no. 18, pp. 2474-2479, 2007.

[33] X.-L. She, G.-J. Song, J.-J. Li, et al., "Non-polar polymer nanotubes and nanowires fabricated by wetting anodic aluminium oxide template," Polymer Journal, vol. 38, no. 7, pp. 639-642, 2006.

[34] J. Qiao, X. Zhang, X. Meng, S. Zhou, S. Wu, and S.-T. Lee, "Morphology-controllable preparation of 1D poly(vinyl pyrrolidone) nanostructured arrays," Nanotechnology, vol. 16, no. 4, pp. 433-436, 2005.

[35] Y. Li, X.-F. Yin, F.-R. Chen, H.-H. Yang, Z.-X. Zhuang, and X.-R. Wang, "Synthesis of magnetic molecularly imprinted 
polymer nanowires using a nanoporous alumina template," Macromolecules, vol. 39, no. 13, pp. 4497-4499, 2006.

[36] X.-L. She, G.-J. Song, Z. Peng, et al., "Nanocables prepared from polyamide 66 nanotubes enveloping Pt nanowires by: a secondary-template method," Polymer Journal, vol. 39, no. 10, pp. 1025-1029, 2007.

[37] J.-J. Li, G.-J. Song, X.-L. She, P. Han, Z. Peng, and D. Chen, "Assembly, morphology and thermal stability of polyamide 6 nanotubes," Polymer Journal, vol. 38, no. 6, pp. 554-558, 2006.

[38] X.-L. She, G.-J. Song, J.-J. Li, P. Han, S. Yang, and Z. Peng, "Preparation and characterization of polyamide 66 nanotubes and nanowires on an anodic aluminum oxide template by a physical wetting method," Journal of Materials Research, vol. 21, no. 5, pp. 1209-1214, 2006.

[39] R. O. Al-Kaysi, R. J. Dillon, L. Zhu, and C. J. Bardeen, "Template assisted synthesis of silica-coated molecular crystal nanorods: from hydrophobic to hydrophilic nanorods," Journal of Colloid and Interface Science, vol. 327, no. 1, pp. 102-107, 2008.

[40] R. O. Al-Kaysi, R. J. Dillon, J. M. Kaiser, L. J. Mueller, G. Guirado, and C. J. Bardeen, "Photopolymerization of organic molecular crystal nanorods," Macromolecules, vol. 40, no. 25, pp. 9040-9044, 2007.

[41] L. Zhang, C. Pan, J. Zhu, and C. Wang, "Synthesis and characterization of Nafion ${ }^{\circledR}-115$ nanowire arrays," Nanotechnology, vol. 16, no. 10, pp. 2242-2244, 2005.

[42] S. Lee, A. M. Müller, R. O. Al-Kaysi, and C. J. Bardeen, "Using perylene-doped polymer nanotubes as fluorescence sensors," Nano Letters, vol. 6, no. 7, pp. 1420-1424, 2006.

[43] M. Zhang, P. Dobriyal, J.-T. Chen, T. P. Russell, J. Olmo, and A. Merry, "Wetting transition in cylindrical alumina nanopores with polymer melts," Nano Letters, vol. 6, no. 5, pp. 1075-1079, 2006.

[44] M. Steinhart, J. H. Wendorff, and R. B. Wehrspohn, "Nanotubes à la carte: wetting of porous templates," ChemPhysChem, vol. 4, no. 11, pp. 1171-1176, 2003.

[45] M. Steinhart, J. H. Wendorff, A. Greiner, et al., "Polymer nanotubes by wetting of ordered porous templates," Science, vol. 296, no. 5575, p. 1997, 2002.

[46] L. Liu, C. Zhao, Y. Zhao, et al., "Characteristics of polypyrrole (PPy) nano-tubules made by templated ac electropolymerization," European Polymer Journal, vol. 41, no. 9, pp. 2117-2121, 2005.

[47] Y. Berdichevsky and Y.-H. Lo, "Polypyrrole nanowire actuators," Advanced Materials, vol. 18, no. 1, pp. 122-125, 2006.

[48] R. Xiao, S. I. Cho, R. Liu, and S. B. Lee, "Controlled electrochemical synthesis of conductive polymer nanotube structures," Journal of the American Chemical Society, vol. 129, no. 14, pp. 4483-4489, 2007.

[49] L. Heng, J. Zhai, A. Qin, et al., "Fabrication of hexaphenylsilole nanowires and their morphology-tunable photoluminescence," ChemPhysChem, vol. 8, no. 10, pp. 1513-1518, 2007.

[50] Q. Liu, Y. Li, H.-G. Liu, et al., "Nanotubes fabricated from sandwich-type mixed (Porphryinato) (phthalocyaninato)europium complex by template technique," The Journal of Physical Chemistry C, vol. 111, no. 20, pp. 7298-7301, 2007.

[51] H. Liu, Y. Li, L. Jiang, et al., "Imaging as-grown [60]fullerene nanotubes by template technique," Journal of the American Chemical Society, vol. 124, no. 45, pp. 13370-13371, 2002.

[52] L. Zhao, W. Yang, Y. Ma., J. Yao, Y. Li, and H. Liu, "Perylene nanotubes fabricated by the template method," Chemical Communications, no. 19, pp. 2442-2443, 2003.
[53] X. Zhang, W. Ju, M. Gu, et al., "A facile route to fabrication of inorganic-small organic molecule cable-like nanocomposite arrays," Chemical Communications, no. 33, pp. 4202-4204, 2005.

[54] H. Gan, H. Liu, Y. Li, et al., "Template synthesis and characterization of chiral organic nanotubes and nanowires," Chemical Physics Letters, vol. 399, no. 1-3, pp. 130-134, 2004.

[55] L. Zhao, W. Yang, G. Zhang, T. Zhai, and J. Yao, "Templatebased melting-recrystallization route to organic nanotubes," Chemical Physics Letters, vol. 379, no. 5-6, pp. 479-483, 2003.

[56] C. Barrett, D. Iacopino, D. O'Carroll, et al., "Synthesis of pentacene nanotubes by melt-assisted template wetting," Chemistry of Materials, vol. 19, no. 3, pp. 338-340, 2007.

[57] J.-K. Lee, W.-K. Koh, W.-S. Chae, and Y.-R. Kim, "Novel synthesis of organic nanowires and their optical properties," Chemical Communications, no. 2, pp. 138-139, 2002.

[58] L. Qu and G. Shi, "Crystalline oligopyrene nanowires with multicolored emission," Chemical Communications, no. 24, pp. 2800-2801, 2004.

[59] H.-X. Ji, J.-S. Hu, Q.-X. Tang, W.-P. Hu, W.-G. Song, and L.J. Wan, "Bis(ethylenedithio)tetrathiafulvalene charge-transfer salt nanotube arrays," Advanced Materials, vol. 18, no. 20, pp. 2753-2757, 2006.

[60] R. Bai, M. Ouyang, R.-J. Zhou, M.-M. Shi, M. Wang, and H.Z. Chen, "Well-defined nanoarrays from an n-type organic perylene-diimide derivative for photoconductive devices," Nanotechnology, vol. 19, no. 5, Article ID 055604, 6 pages, 2008.

[61] R. O. Al-Kaysi and C. J. Bardeen, "General method for the synthesis of crystalline organic nanorods using porous alumina templates," Chemical Communications, no. 11, pp. 1224-1226, 2006.

[62] R. O. Al-Kaysi and C. J. Bardeen, "Reversible photoinduced shape changes of crystalline organic nanorods," Advanced Materials, vol. 19, no. 9, pp. 1276-1280, 2007.

[63] Unpublished results.

[64] R. O. Al-Kaysi, A. M. Müller, and C. J. Bardeen, "Photochemically driven shape changes of crystalline organic nanorods," Journal of the American Chemical Society, vol. 128, no. 50, pp. 15938-15939, 2006.

[65] R. O. Al-Kaysi, A. M. Müller, R. J. Frisbee, and C. J. Bardeen, "Formation of cocrystal nanorods by solid state reaction of tetracyanobenzene in 9-methylanthracene molecular crystal nanorods," Journal of Crystal Growth and Design, vol. 9, no. 4, pp. 1780-1785, 2009.

[66] M. A. Garcia-Garibay, "Molecular crystals on the move: from single-crystal-to-single-crystal photoreactions to molecular machinery," Angewandte Chemie-International Edition, vol. 46, no. 47, pp. 8945-8947, 2007. 

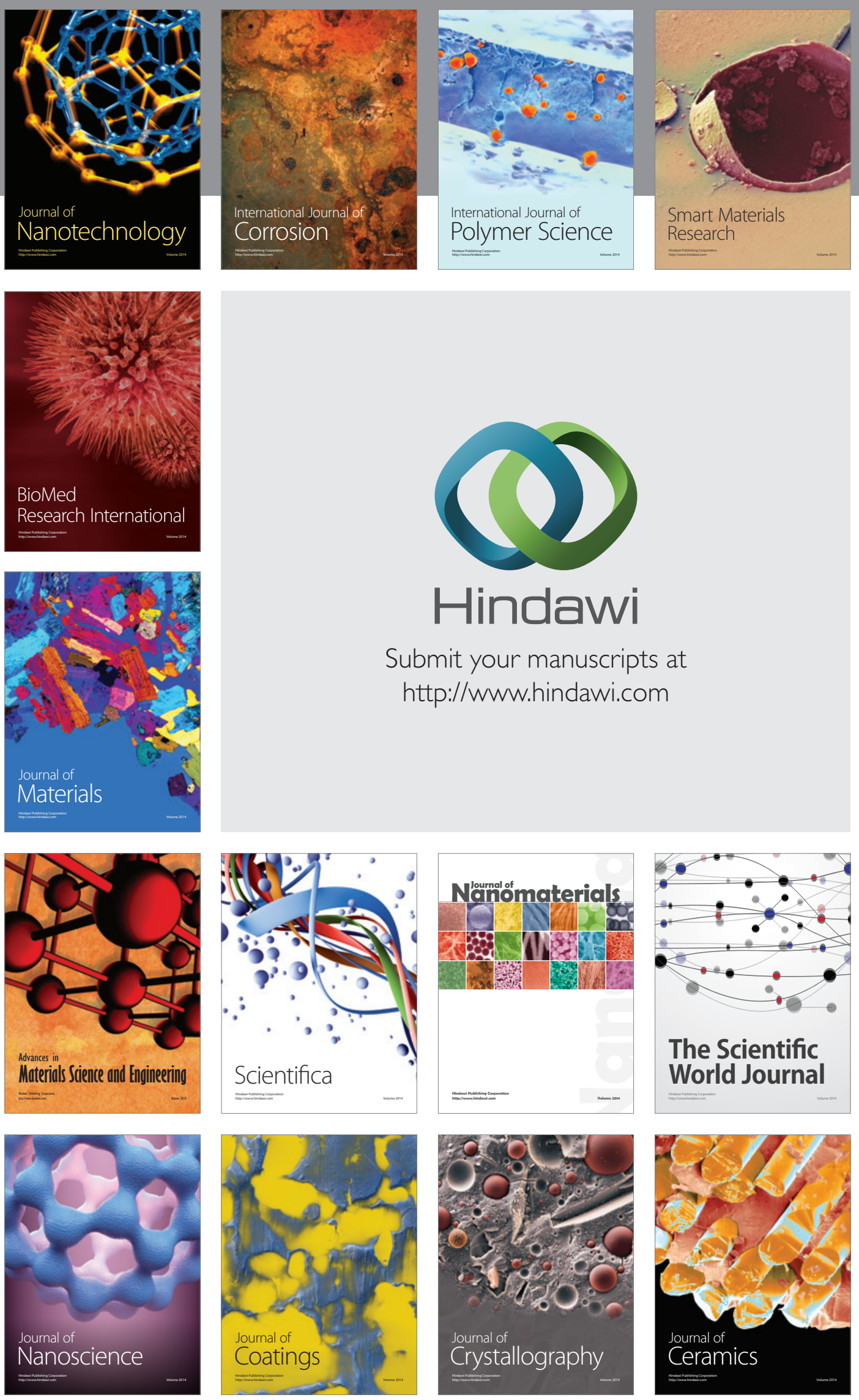

The Scientific World Journal

Submit your manuscripts at

http://www.hindawi.com

\section{World Journal}

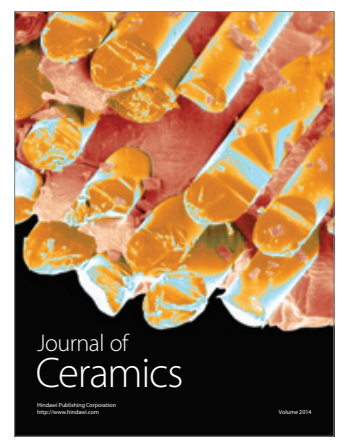

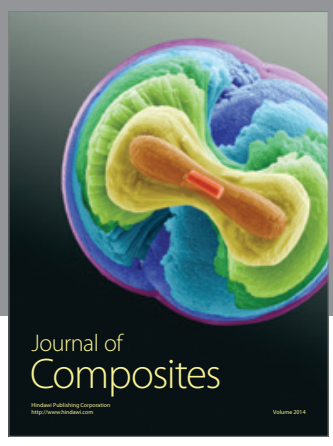
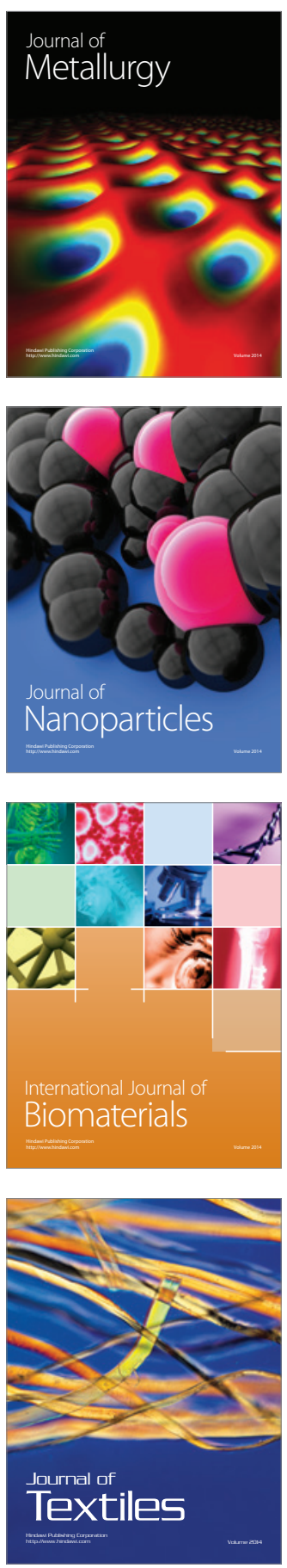